\title{
VITREOUS LOSS IN PLANNED EXTRACAPSULAR CATARACT EXTRACTION DOES LEAD TO A POORER VISUAL OUTCOME
}

\author{
N. A. FROST ${ }^{1}$, J. M. SPARROW ${ }^{2}$, N. P. STRONG ${ }^{3}$ and A. R. ROSENTHAL ${ }^{1}$ \\ Leicester, Bristol and Newcastle upon Tyne
}

\begin{abstract}
SUMMARY
Forty-six cases of vitreous loss during planned extracapsular cataract extraction salvaged by anterior vitrectomy and primary anterior chamber lens implantation were compared in a retrospective cohort study with 92 individually matched controls. The postoperative visual outcome for cases with vitreous loss was significantly poorer than that for controls even after adjustment for confounding variables. Part of this visual morbidity was explained by cystoid macular oedema and retinal detachment, but even after adjusting for these two complications visual outcome remained worse among cases than controls. There was a significantly higher incidence of clinically apparent cystoid macular oedema amongst cases compared with controls $(20 \%$ versus $1 \%)$. Two retinal detachments occurred among the cases but this difference in incidence was not statistically significant.
\end{abstract}

Many issues surrounding accidental vitreous loss at cataract surgery remain unresolved. In contrast to the poor outcome described by Vail, ${ }^{1}$ more recent authors have been more optimisic. $\mathrm{Nishi}^{2}$ found no significant difference in visual acuity between cases of vitreous loss and controls. Osher and Cionni ${ }^{3}$ commented that when properly managed, a torn posterior capsule is compatible with an excellent visual outcome. Spigelman et al. ${ }^{4}$ stated that a quiet eye and visually acceptable results can be accomplished when implanting an intraocular lens following vitreous loss at cataract surgery.

Review of the literature reveals a suspected association between vitreous loss during extracapsular cataract extraction and worse visual outcome. ${ }^{5-7}$

From: ${ }^{1}$ Department of Ophthalmology, Leicester Royal Infirmary; ${ }^{2}$ University Department of Ophthalmology, Bristol Eye Hospital; ${ }^{3}$ Department of Ophthalmology, Royal Victoria Infirmary, Newcastle upon Tyne, UK.

Correspondence to: N. A. Frost, FRCS, MRCP, University Department of Ophthalmology, Bristol Eye Hospital, Lower Maudlin Street, Bristol BS1 2LX, UK.
Definite conclusions are difficult to draw, however, because of the infrequency of this complication and because of the large number of related variables. Despite the perceived importance of intraoperative vitreous loss, previous studies have involved small numbers, ${ }^{2,4,8,9}$ sometimes without clear inclusion and/or exclusion criteria ${ }^{3,7,8}$ and without using suitable controls and/or statistical analysis. ${ }^{3,5,10-12}$ Some studies have combined results from different types of cataract extraction ${ }^{10,11,13,14}$ or combined different forms of salvage procedure..$^{2,3,5,9,15,16}$ The aim of this study was to identify (if present) and quantify visual morbidity associated wth accidental vitreous loss in planned extracapsular cataract extraction.

\section{SUBJECTS AND METHODS}

A retrospective cohort study was undertaken to investigate the visual outcome of cases in which planned extracapsular cataract extraction (ECCE) was complicated by vitreous loss during the period 1 July 1988 to 19 June 1990 . Standard 'extracapsular' and 'endocapsular' extractions were included. (No phacoemulsification procedures were included.) All cases of vitreous loss salvaged by anterior vitrectomy and the primary insertion of an anterior chamber intraocular lens implant (ACL) were identified using the operating theatre records.

The case notes were then examined and exclusion criteria applied. Any cases with a preoperative history or pathology likely to affect the visual outcome were excluded. The criteria for exclusion included previous trauma, intraocular surgery, uveitis, retinal breaks or detachments, clinically apparent diabetic maculopathy, retinal vascular occlusions and amblyopia. Cases of cataract surgery combined with another procedure were also excluded. An exception to the above exclusion rule was applied to age-related macular degeneration (AMD). This was deemed necessary in view of the

Eye (1995) 9, 446-451 ㅇ 1995 Royal College of Ophthalmologists 
difficulty in attributing a visual reduction to the highly variable morphological features of AMD and the high prevalence of AMD features in the age group under study. Gross AMD was noted and adjusted for in the statistical analysis.

Controls who had undergone uncomplicated ECCE with posterior chamber lens (PCL) implantation during the same time-period were found and matched using the same operating theatre records. Controls were selected who individually matched the cases of vitreous loss for age ( \pm 6 years), sex, race, grade of surgeon and anaesthetic type (local or general). Two controls were selected for each case. The selections were made prior to inspection of the notes. The same exclusion criteria were then applied to controls as to cases. If a control had to be excluded another was found by repeating the selection and matching procedure.

The main outcome measure chosen was the Snellen visual acuity as recorded on the latest clinic visit. This was measured firstly with the patient's latest pair of distance spectacles and secondly with pinhole. If spectacles were unavailable the acuity was checked unaided and with pinhole correction. The value chosen for analysis was the best of the recorded values using the above methods. Credit was given only for lines which were fully read, partially read lines being ignored.

The post-operative incidence of retinal detachment (RD), clinically apparent cystoid macular oedema (CMO) and the commencement of treatment for raised intraocular pressure (IOP) were all recorded.

\section{Statistical Methods}

Cases and controls were checked for comparability and efficiency of matching by comparing the two groups. Age and follow-up time between the two groups were compared using $t$-tests. Sex, race, grade of surgeon, admission type (day case or inpatient) and anaesthetic type (general or local) were compared between the two groups by chi-squared tests.

Two methods of multivariate regression analysis were used to examine the relationship between the variables of interest and visual outcome. The first method was a standard logistic regression. The second method consisted of a regression after conversion of Snellen acuities to a LogMAR format. The results of both methods of analysis are presented for comparison. In each method the analysis was a two-stage procedure. The first stage (first statistical model) in each method was an analysis of those variables which were fixed at, or prior to, the time of onset of the patient's surgery. The purpose of this was to determine whether any of these 'pre-existing' variables was significantly related to visual outcome. The first statistical model included age, sex, race, the presence of gross AMD, admission type, anaesthetic type and the grade of operating surgeon. The second statistical model examined the post-operative variables related to incident complications, namely CMO, RD and raised IOP and their possible relationship to visual outcome, whilst taking into account the effects of age, sex and any other 'pre-existing' variables which had been statistically significant in the first statistical model. If a 'preexisting' variable was identified as significant by the first statistical model using either method (logistic or LogMAR) it was incorporated into both the second models (logistic and LogMAR); thus both second models included the same set of variables.

The logistic regression used visual outcome categories of $6 / 12$ or better versus $6 / 18$ or worse. For the LogMAR method of regression analysis the Snellen data were converted into a LogMAR format by taking the $\log$ of the reciprocal of the Snellen fraction. This transformation correctly identifies the position of the Snellen lines along a continuous arithmetically progressing scale. ${ }^{17}$ In order to position the small number of non-Snellen acuities on the visual angle scale an arbitrary doubling of the visual angle was assigned to the difference between $6 / 60$ and 'counting fingers' $(\mathrm{CF})$ and similarly between $\mathrm{CF}$ and 'hand movements' (HM). (These assigned values correspond to $3 / 60$ for $\mathrm{CF}$ and $1.5 / 60$ for $\mathrm{HM}$, which are probably an understatement of the visual loss, i.e. it is unlikely that a patient with HM vision would see 1.5/60 Snellen and the assignment would therefore underestimate the importance of differences at this end of the scale.)

The rates of the complications (CMO, RD and raised IOP) in cases and controls were compared using Fisher's exact tests.

Finally a subgroup analysis was performed on the vitreous loss cases to examine visual outcome and CMO (dependent variables) in terms firstly of the method of vitrectomy and secondly of the efficacy of vitrectomy as judged by the post-operative presence of vitreous in the anterior chamber or the wound.

\section{RESULTS}

During the study period approximately 2350 cataract extractions were performed. These were mostly ECCE using a variety of PCLs. Ocutome, Kaufmann or 'sponge' vitrectomies were used to manage vitreous loss in the study cases and Pharmacia Synflex 350A or 350B ACLs were implanted. Seventy-one cases of vitreous loss were identified during the study period. Only one set of hospital records could not be located in our search and this patient may or may not have been a case of vitreous loss. It is therefore likely that the vast majority of relevant cases in this study period were successfully 
Table I. Exclusion procedure: reasons for exlusion among cases and controls

\begin{tabular}{|c|c|c|c|c|}
\hline & Vitreous loss cases & & Matched controls & \\
\hline Initial number selected & 71 & & 107 & \\
\hline Exclusions & $\begin{array}{l}\text { Previous surgery } \\
\text { Diabetic maculopathy } \\
\text { Trauma } \\
\text { Central retinal vein occlusion } \\
\text { Amblyopia } \\
\text { Previous iritis } \\
\text { Previous retinal tear } \\
\text { Previous retinal detachment } \\
\text { Expulsive haemorrhage } \\
\text { Combined procedure } \\
\text { Other pathology } \\
\text { Inadequate follow-up } \\
\quad \text { Total }\end{array}$ & $\begin{array}{r}4 \\
4 \\
2 \\
2 \\
2 \\
1 \\
1 \\
1 \\
1 \\
1 \\
3 \\
3 \\
25\end{array}$ & $\begin{array}{l}\text { Previous surgery } \\
\text { Diabetic maculopathy } \\
\text { Trauma } \\
\text { Central retinal vein occlusion } \\
\text { Previous retinal detachment } \\
\text { Combined procedure } \\
\text { Other pathology } \\
\text { Inadequate follow-up } \\
\text { Total }\end{array}$ & $\begin{array}{r}3 \\
2 \\
1 \\
1 \\
1 \\
2 \\
2 \\
3 \\
15\end{array}$ \\
\hline Remaining subjects for analysis & 46 & & 92 & \\
\hline
\end{tabular}

identified. Following application of exclusion criteria 46 cases with vitreous loss remained, for whom 92 controls were then selected. The exclusions occurred for a wide variety of reasons which are listed in Table I. The characteristics of the cases and controls (after exclusions) are presented in Table II. The mean age for both groups was approximately 70 years. The mean follow-up period for both groups was approximately 20 months. Outcomes are presented in Table III and discussed in detail below. Final visual acuities are presented in Fig. 1. Sixty-five per cent of the vitreous loss cases achieved a final post-operative visual acuity of $6 / 12$ or better compared with $90 \%$ of the controls.

There were no significant group differences between cases and controls for age, sex, race, grade of surgeon, type of admission (day case or inpatient), anaesthetic type or follow-up period ( $p>0.7$ for all), thus confirming the effectiveness of the matching procedure. Incomplete matching for race occurred for one patient with vitreous loss (see Table II).

Of the pre-existing variables older age and presence of gross AMD were both powerfully associated with a worse visual outcome (Table IV). The grade of surgeon was relevant to visual outcome only in the logistic regression analysis. The other variables which were fixed at the time of onset of surgery (sex, race, admission type, anaesthetic type) were not significantly related to visual outcome by either logistic or regression analysis. After multivariate adjustment for each of these variables vitreous loss remained powerfully associated with a worse visual outcome $(p \leqslant 0.000020$ by both logistic and LogMAR methods: see Table IV). In the logistic regression analysis the odds ratio (OR) for a poorer visual outcome (6/12 or better versus $6 / 18$ or worse) was 17 (95\% CI 3.8-78). In the LogMAR analysis, after accounting for the confounding variables, the visual angle of the vitreous loss group was on average 1.60 (95\% CI $1.30-1.97)$ times worse than that of controls. This effect approximates to a little over 1 Snellen line difference; for example, at the better end of the Snellen range this change would be equivalent to a drop from $6 / 6$ to $6 / 9$ part, and at the worse end from $6 / 24$ to $6 / 36$ part.

After adjustment for age, sex and any other significant 'confounders' identified in the first statistical model, CMO and RD were significant contributors to a poorer visual outcome in the second statistical model (Table IV). This poorer outcome was similar in the two types of analysis. In the logistic regression the OR for having a vision of $6 / 18$ or worse was 30 (95\% CI 2.6-350). In the LogMAR analysis the impact of CMO on vision was such that the visual angle was approximately doubled among subjects with this complication (1.92 times worse; $95 \%$ CI 1.42-2.60). The number of eyes with RD was small, which renders average effect sizes rather meaningless, although it is reasonable to comment that the eyes with RD both ended up with poor vision. Post-operative ocular hypertension/glaucoma treatment was not significantly related to visual outcome. Even after adjusting for both 'pre-existing' and 'complicating' variables vitreous loss remained significantly associated with a worse visual outcome in both analyses $(p \leqslant 0.010$ by logistic and

Table II. Characteristics of the study population (after exclusions)

\begin{tabular}{lll}
\hline & Vitreous loss cases & Matched controls \\
\hline Mean age: & 70.4 years (SD 11.4) & 70.5 years (SD 11.3) \\
Sex: & Male, 21; female, 25 & Male, 42; female, 50 \\
Race: & Asian, 11; Caucasian, 34; Black 1 & Asian, 22; Caucasian, 70 \\
Mean follow-up: & 19.7 months (SD 10.9) & 20.3 months (SD 12.3) \\
\hline
\end{tabular}


Table III. Post-operative outcome: incident complications, AMD and final acuity

\begin{tabular}{|c|c|c|c|c|}
\hline & Vitreous loss cases & & Matched controls & \\
\hline Complications & $\begin{array}{l}\text { Cystoid macular oedema } \\
\text { Retinal detachment } \\
\text { Raised intraocular pressure } \\
\text { Bullous keratopathy } \\
\text { Haptic protrusion } \\
\text { Iris prolapse }\end{array}$ & $\begin{array}{l}9(20 \%) \\
2(4 \%) \\
4(9 \%) \\
0 \\
1 \\
1\end{array}$ & $\begin{array}{l}\text { Cystoid macular oedema } \\
\text { Retinal detachment } \\
\text { Raised intraocular pressure } \\
\text { Bullous keratopathy } \\
\text { Haptic malposition } \\
\text { Endophthalmitis }\end{array}$ & $\begin{array}{l}1(1 \%) \\
0 \\
0 \\
0 \\
1 \\
1\end{array}$ \\
\hline Poor visual acuity attributed to AMD & & & 6 & \\
\hline Final visual acuity & $65 \% \geqslant 6 / 12$ & & $90 \% \geqslant 6 / 12$ & \\
\hline
\end{tabular}

AMD, age-related macular degeneration.

LogMAR methods: see Table IV). In the LogMAR analysis after accounting for both 'pre-existing' and 'complicating' variables the impact of this effect on vision was such that the visual angle of the vitreous loss group was on average 1.26 (95\% CI 1.06-1.49) times worse than that of the controls. This effect approximates to half a Snellen line difference; for example, at the better end of the Snellen range this residual unexplained visual morbidity would be equivalent to a drop from $6 / 6$ to $6 / 7.5$, and at the worse end from $6 / 24$ to $6 / 30$. In the logistic regression analysis the OR for a poorer visual outcome (6/12 or better versus $6 / 18$ or worse) was 11 (95\% CI 1.8-65). This latter effect on visual outcome represents a residual 'unaccounted for' visual morbidity among the cases of vitreous loss.

There was a significantly higher post-operative incidence of clinically apparent $\mathrm{CMO}$ amongst cases of vitreous loss compared with controls (20\% versus $1 \% ; p=0.00021$, by chi-squared test). Four patients

Table IV. The $p$ values from multivariate analyses of visual acuity outcome by: (1) logistic regression using $6 / 12$ or better versus $6 / 18$ or worse as a separation criterion and (2) multiple regression using LogMAR conversion of Snellen data

\begin{tabular}{lcc}
\hline & \multicolumn{2}{c}{$p$ value } \\
\cline { 2 - 3 } Variable & $\begin{array}{c}\text { Logistic } \\
\text { regression }\end{array}$ & $\begin{array}{c}\text { 'LogMAR' } \\
\text { regression }\end{array}$ \\
\hline First model & & \\
Age & 0.067 & 0.000086 \\
Sex & 0.22 & 0.61 \\
Race & 0.87 & 0.35 \\
AMD & $<10^{-6}$ & $<10^{-6}$ \\
Admission type & 0.80 & 0.99 \\
Anaesthetic type & 0.44 & 0.18 \\
Grade of surgeon & 0.0092 & 0.71 \\
Vitreous loss & 0.000017 & 0.000020 \\
Second model & & \\
Age & 0.067 & $<10^{-6}$ \\
Sex & 0.22 & 0.49 \\
AMD & $<10^{-6}$ & $<10^{-6}$ \\
Grade of surgeon & 0.015 & 0.45 \\
CMO & 0.00038 & 0.000002 \\
RD & 0.00045 & $<10^{-6}$ \\
Raised IOP & 0.87 & 0.62 \\
Vitreous loss & 0.0036 & 0.010 \\
\hline The first model included & con &
\end{tabular}

The first model included confounding variables which existed at the time of surgery and which were suspected of having relevance to visual outcome. The second model included all significant confounders from the first model together with variables related to surgical complications of relevance to visual outcome. with vitreous loss started treatment for raised IOP in the follow-up period. None of the controls required such treatment ( $p=0.011$, by chi-squared test). Two RDs occurred among the cases and none among controls. This difference in incidence between the groups was not significant ( $p=0.11$, by chi-squared test).

A subgroup analysis was performed to examine the effect of the method of vitrectomy. In terms of both visual outcome and post-operative CMO no differences were detected between the patients who had formal vitrectomies, sponge vitrectomies or where the method of vitrectomy was unspecified. The post-operative presence of vitreous in the anterior chamber or the wound had no significant effect on the visual outcome. The numbers in each subgroup, however, were small.

\section{DISCUSSION}

In this study there were relatively large numbers of similarly managed cases. Rigorous inclusion and exclusion criteria were applied and adjustment was made for potentially confounding variables. These methodological features represent an improvement on previous studies on the impact of accidental vitreous loss in cataract surgery.

The corrected visual acuity was tested using spectacles rather than a refraction on the day, which creates the potential for inaccuracy due to refractive error; however, this will have been largely compensated for by the use of the pinhole.

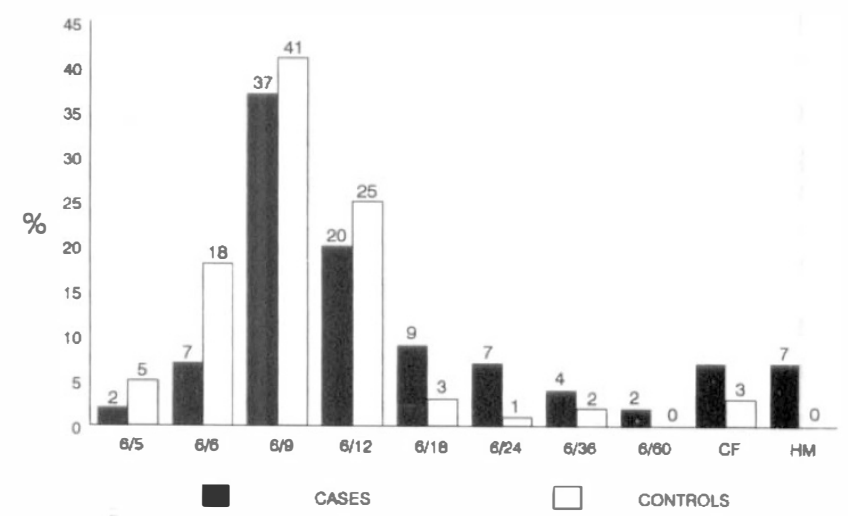

Fig. 1. Distribution of final visual acuity for vitreous loss cases and controls. 
The role of age-related macular changes in determining visual outcome is problematic. The extent to which observed macular change influences visual acuity is difficult to judge, and a clinical decision that suboptimal post-operative visual acuity is due to AMD is generally very subjective. Casecontrol matching for age and age adjustment in the multivariate analyses will have corrected in part for this problem. Furthermore there was a significant difference in final visual acuity even after adjusting for those cases where the reduced visual acuity was attributed to unequivocal AMD. Thus the patient matching and adjustments for age and clinically evident AMD in this study should take account of this confounding effect.

An ACL will give a slightly more magnified retinal image than a PCL, but this effect would have acted to reduce, not enhance, the magnitude of the reduction in visual acuity in the vitreous loss group.

It is notable that considerably more patients had to be excluded from the initial vitreous loss group (25/ 71) compared with the number excluded from the initial control group (15/107). This may in part reflect a predisposition to vitreous loss in certain instances (e.g. previous trauma) but it may also reflect a desire to attribute poor post-operative visual acuity to causes other than vitreous loss (e.g. amblyopia) and for this reason our exclusion procedure may in fact have caused underestimation of the excess visual morbidity associated with vitreous loss.

The visual acuity results in this study are similar to those of Balent et al. ${ }^{5}$ and Siepser and Kline, ${ }^{7}$ but in these studies there was no statistical comparison between vitreous loss cases and controls. Nishi ${ }^{2}$ found no significant difference in visual acuity between cases of vitreous loss and (unmatched) controls; however, only 18 cases of vitreous loss were involved and both ACLs and PCLs were implanted. A series of 20 cases of vitreous loss managed by vitrectomy plus either iris clip-lens or ACL was reported by Jaffe et al. ${ }^{12}$ in which $85 \%$ achieved a visual acuity of $20 / 40$ or better at $12-14$ months follow-up (no controls). In Osher and Cionni's ${ }^{3}$ series of 48 cases of torn posterior capsule anterior vitrectomy was performed in 18 cases and ACL implanted in 4 cases. Eighty-nine per cent achieved a VA of 20/40 or better; however, no analysis of subgroups or controls was presented. Spigelman et $a l .{ }^{4}$ reported a 'favourable' visual outcome following vitreous loss but 20 out of their 26 cases were managed by PCL implants. The variation in these results is likely to be due to small case numbers and the different types of salvage procedure adopted. The issue of visual outcome for cases salvaged by vitrectomy plus ACL is now somewhat clearer, but the question of visual outcome for cases managed by
PCL implantation compared with controls remains unresolved.

An association of CMO and defects in the posterior capsule or zonule with or without vitreous loss has been reported following ECCE. ${ }^{11,15,18-20}$ The variation in frequency between studies is considerable due to methodological differences. The incidence of $\mathrm{CMO}$ in this study is not inconsistent with the literature.

Neither of the eyes with retinal detachment in our series had axial lengths greater than $24.5 \mathrm{~mm}$. A suspected association between defects in the posterior capsule and retinal detachment has previously been documented. ${ }^{21-23}$ An association between vitreous loss during cataract surgery and retinal detachment has been reported by Javitt et al..$^{24}$ however, Nd:YAG laser posterior capsulotomy also appears to be a risk factor for RD. ${ }^{25}$ Thus it is not clear whether anterior vitreous prolapse with a consequent increase in retinal traction leads to retinal detachment or whether a more complex mechanism operates. Analysis of the true relationship of vitreous loss with retinal detachment has been made difficult (in this study also) by the small number of patients suffering this complication following vitreous loss during cataract surgery.

The choice of which intraocular lens to implant in the event of vitreous loss remains controversial. Balent et al..$^{5}$ found that lens type did not appear to influence final visual acuity. They also could see no clear association between any cause of visual loss and a specific lens type. In contrast Johansen et al. ${ }^{16}$ found that their group of cases with an ACL had a significantly poorer post-operative visual acuity than their groups of cases with a PCL; however, numbers were small and anterior vitrectomy was not performed in every case. The literature suggests that a PCL should be implanted where possible but a case for this view has not been convincingly demonstrated. In the absence of posterior capsular support a PCL may still be implanted. The visual outcome with iris-supported and scleral fixated PCLs remains to be determined.

\section{CONCLUSION}

Vitreous loss, when salvaged by anterior vitrectomy and primary anterior chamber lens implantation in planned extracapsular cataract extraction, does lead to a poorer visual outcome. This hazard to visual outcome is in part explained by post-operative clinically apparent cystoid macular oedema and, in a small number of cases, retinal detachment.

The authors are grateful to the consultants of the Department of Ophthalmology, Leicester Royal Infirmary, for allowing their patients to be included in this study.

Key words: Cataract extraction, Visual outcome, Vitreous loss. 


\section{REFERENCES}

1. Vail D. After results of vitreous loss. Am J Ophthalmol 1965;59:573-86.

2. Nishi O. Vitreous loss in posterior chamber lens implantation. J Cataract Refract Surg 1987;13:424-7.

3. Osher RH, Cionni RJ. The torn posterior capsule: its intraoperative behaviour, surgical management and long term consequences. J Cataract Refract Surg 1990;16:490-4.

4. Spigelman AV, Lindstrom RL, Nichols BD, Lindquist TD. Visual results following vitreous loss and primary lens implantation. J Cataract Refract Surg 1989;15:2014.

5. Balent A, Civerchia LL, Mohamadi P. Visual outcome of cataract extraction and lens implantation complicated by vitreous loss. J Cataract Refract Surg 1988;14:158-60.

6. Pearson PA, Owen DG, Maliszewski M, Smith TJ. Anterior chamber lens extraction after vitreous loss. $\mathrm{Br}$ J Ophthalmol 1989;73:596-9.

7. Siepser SB, Kline OR. Aborted posterior chamber intraocular lens insertions: a 'second choyce'. Am Intraocular Implant Soc J 1984;10:51-2.

8. Shah NA, Adrianwala SD, Gondhalekar NA. Intraocular lens implantation after vitreous loss. J Postgrad Med 1991;37:205-8.

9. Claoue C, Steele A. Visual prognosis following accidental vitreous loss during cataract surgery. Eye 1993;7:735-9.

10. Berger BB, Zweig KO, Peyman GA. Vitreous loss managed by anterior vitrectomy. Arch Ophthalmol 1980;98:1245-7.

11. Harris WS, Taylor BC, Winslow RL. Cystoid macular edema following intraocular lens implantation. Ophthalmic Surg 1977;8:134-7.

12. Jaffe NS, Clayman HM, Jaffe MS, Light DS. The results of lens implantation in eyes with operative loss of vitreous. Am Intraocular Implant Soc J 1980;6:243-5.

13. Kennedy JE, Flaherty MP, Hunyor ABL, Robinson LP. Evaluation of nine hundred and sixty-seven consecutive intraocular implants. Aust NZ J Ophthalmol 1985;13:349-52.
14. Mazzocco TR. Intraocular lens implantation following vitreous loss. Int Ophthalmol Clin 1979;19:155-64.

15. Chambless WS. Phacoemulsification and the retina. Ophthalmology 1979;86:2019-22.

16. Johansen JJ, Theodorsen FP, Corydon L. Visual outcome following complicated extracapsular cataract extraction. J Cataract Refract Surg 1992;18:577-81.

17. Moseley MJ, Jones HS. Visual acuity: calculating appropriate averages. Acta Ophthalmol (Copenh) 1993;71:296-300.

18. Jaffe NS, Clayman HM, Jaffe MS. Cystoid macular edema after intracapsular and extracapsular cataract extraction with and without an intraocular lens. Ophthalmology 1982;89:25-9.

19. Kraff MC, Sanders DR, Jampol LM, Lieberman HL. Effect of primary capsulotomy with extracapsular surgery on the incidence of pseudophakic cystoid macular edema. Am J Ophthalmol 1984;98:166-70.

20. Winslow RL, Taylor BC, Harris WS. A one-year follow-up of cystoid macular edema following intraocular lens implantation. Ophthalmology 1978;85:190 6.

21. Coonan P, Fung WE, Webster RG, Allen AW, Abbott RL. The incidence of retinal detachment following extracapsular cataract extraction: a ten-year study. Ophthalmology 1985;92:1096-101.

22. Hurite FG, Sorr EM, Everett WG. The incidence of retinal detachment following phacoemulsification. Ophthalmology 1979;86:2004-6.

23. Kraff MC, Sanders DR. Incidence of retinal detachment following posterior chamber intraocular lens surgery. J Cataract Refract Surg 1990;16:477-80.

24. Javitt JC, Vitale S, Canner JK, Krakauer H, McBean AM, Sommer A. National outcomes of cataract extraction. I. Retinal detachment after inpatient surgery. Ophthalmology 1991;98:895-902.

25. Javitt JC, Tielsch JM, Canner JK, Kolb MM, Sommer A, Steinberg EP. National outcomes of cataract extraction: increased risk of retinal complications associated with Nd:YAG laser capsulotomy. Ophthalmology 1992;99:1487-98. 